fournal of Medical Genetics (1972). 9, 401.

\title{
A New Genetic Variant of the Spinal Muscular Atrophies in Infancy*
}

\author{
H. ZELLWEGER, E. HANHART, and H. J. SCHNEIDER
}

From the University Children's Clinics, Berne and Zürich, Switzerland

The proximal spinal muscular atrophies (SMAs) represent clinically and genetically a heterogeneous group of conditions which have in common a more or less slowly progressive degeneration and ultimate disappearance of the anterior horn cells in the spinal cord and to a lesser extent of the motor nuclei in the brainstem. The latter are in most instances not associated with clinical manifestations with the exception of the frequent occurrence of fasciculations in the tongue.

The clinical classification of the SMAs meets with difficulties since they form a continuous spectrum from cases with prenatal onset to cases which develop clinical mainifestations after many years (Zellweger et al, 1969a). The rapidity of progression and severity of the clinical picture vary likewise.

Classification of the SMAs on the basis of their genetics is possible, however, at least for familial cases, since various patterns of hereditary transmission are encountered (Zellweger, 1971). Autosomal recessive inheritance is most frequent. Autosomal dominant inheritance with complete or with incomplete penetrance is second in frequency, while X-linked recessive inheritance has been observed in very few instances. Several authors described familial SMA affecting more or less distant relatives indicating a hereditary pattern incompatible with any of the above listed types of inheritance (Brandt, 1950; Wohlfart, Fex, and Eliasson, 1955; Kugelberg and Welander, 1956; Kirchhof, Kumral, and Fadiloglu, 1962; Becker, 1964 and 1966; Zellweger, Schneider, and Schuldt, 1969b; White and Blaw, 1971). Becker (1966) analysed this peculiar mode of inheritance and put forward the hypothesis that there are at least 3 allelomorphic genes on the locus of this particular SMA: the wild type gene a, the mutant gene $A$, and another allele called $a^{\prime}$ or activator allele. The genotypes $\mathrm{Aa}$ and

\footnotetext{
Received 17 April 1972.

* Reprint requests to H. Zellweger, Department of Pediatrics University Hospitals, Iowa City, Iowa, USA.
}

a'a are phenotypically normal, genotype Aa does not show any clinical signs of SMA, and the disease becomes apparent only in individuals with the genotype $\mathrm{Aa}^{\prime}$; in other words $\mathrm{a}^{\prime}$ is responsible for the penetrance of the mutant gene A. Offspring of healthy parents with the 2 genotypes $A a$ and a'a can have 4 possible genotypes, namely $\mathrm{Aa}, \mathrm{a}^{\prime} \mathrm{a}$, aa (not affected), and $\mathrm{Aa}^{\prime}$ (affected with SMA). The risk of SMA in the offspring of parents with the above genotypes is therefore $25 \%$.

The activator allele $a^{\prime}$ is, according to Becker, more frequent than the mutant gene $A$ and about 10 or more times less frequent than the wild gene $a$. Thus, coincidental association of a'a genotypes with Aa relatives may occur more than once in a SMA kindred carrying the mutant gene A. Details of this hereditary variant of SMA have been described elsewhere (Zellweger et al, 1969b). It is the purpose of this presentation to report further observations of familial SMA where this type of inheritance may be instrumental.

\section{Material and Methods}

One of the authors (E.H.) collected all cases of infantile SMA or Werdnig-Hoffmann's disease registered in the archives of the 5 university children's clinics and of various other children's hospitals in Switzerland. All cases admitted between 1910 and 1970 (March) were included. Inquiries concerning these children and their ancestry were made during visits to their homes. Ancestry was studied as far back as possible by consulting various available sources such as family bibles, birth registries, church registries, etc. By these means it was possible to follow back some kindreds for 6 to 8 though, rarely more, generations. Patients registered in the various hospitals as being affected with KugelbergWelander's disease are not included here unless they were related to known cases of infantile SMA.

\section{Results}

The investigations yielded 104 sibships with altogether 150 patients with infantile SMA. The diagnosis was confirmed in most instances by a neuropathic electromyogram (EMG), by the finding 
of neurogenic atrophies in the muscle biopsy, and by characteristic necropsy findings in the spinal cord. Some of the cases observed in earlier years did not have muscle biopsies or necropsies and were included merely because of the typical clinical findings and because other cases in the same family were histologically proven cases of SMA.

Thirty-four families were found with more than one case of SMA and in 7 of them SMA was found in more than one sibship or more than one generation. One of them concerned affected children of 2 brothers who had married 2 sisters of an unrelated family. A short description of the SMA in the other 6 kindreds including an abbreviated pedigree is given below.

\section{Case Reports and Pedigrees}

\section{Kindred 1 (Fig. 1)}

Case 1(III.6;2.9.1965-17.9.1966) was the product of the mother's 3 rd pregnancy. Delivery was 7 days late, birthweight was $4000 \mathrm{~g}$. At the age of 3 months it was noticed that the child was unable to lift her head in a supine position. The child became progressively limp in the next months, and was hospitalized (University Children's Clinic, Berne-17308/66) at the age of 4 months, where advanced SMA was diagnosed and confirmed by EMG and muscle biopsy. Serum creatophosphokinase (CPK) was within normal range. Severe involvement of the intercostal muscles ensued and death occurred at the age of $12 \frac{1}{2}$ months.
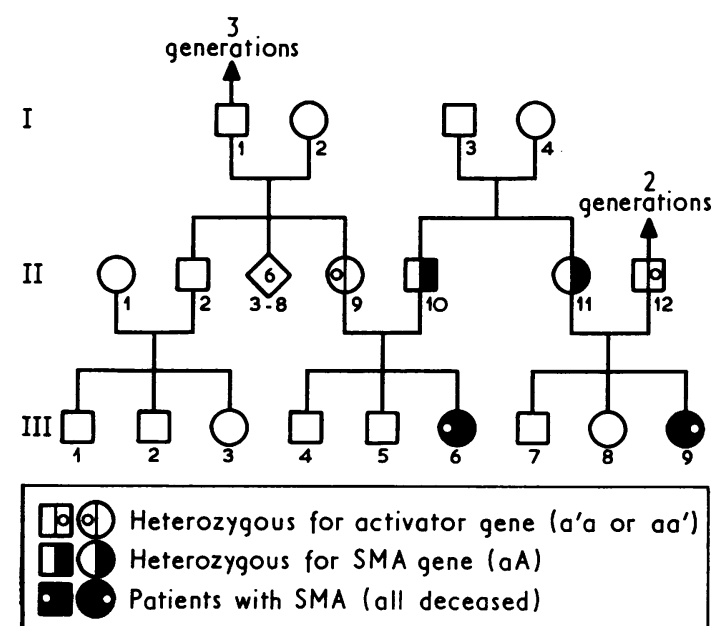

Fig. 1. Abbreviated pedigree of kindred 1. There are 2 firstdegree cousins with infantile SMA. The father of III.6 (case 1) and the mother of III.9 (case 2) are sibs; neither show evidence of SMA. The respective spouses (II.9 and II.12) are presumptive carriers of the activator allele. The key given here is for Figs 1-4 and Fig. 6 . In patients who are heterozygous for the activator and SMA gene, where the gene originates from different, non-related families this is distinguished by the ring being on the left (eg, case II.9) or on the right (eg, case II. 12).
Case 2 (III.9; 24.3.1968-26.1.1970) was the product of the mother's 3 rd and uneventful pregnancy. Fetal movements were marked. At 4 weeks of age it was noticed that the infant did not move as well as did 2 older normal sibs at the same age. At the age of 3 months the child was hospitalized in the University Children's Clinic, Berne (26211/69) where the diagnosis of advanced SMA was made and confirmed by EMG and muscle biopsy. The child died at the age of 10 months.

Genealogy of Kindred 1. Cases 1 and 2 are first cousins, the father (II.10) of case 1 and the mother (II.11) of case 2 being sibs. No consanguinity was found in the ancestry of these families who came from various areas of the Canton Berne. The occurrence of Duchenne muscular dystrophy in a first cousin (III.1) of case 1 is probably coincidental. It could be the result of a point mutation. If it were inherited, the mutant gene would come from this patient's mother (II.1) who is not related to our SMA patients.

\section{Kindred 2 (Fig. 2)}

Case 3 (IV.1; 13.5.-18.11.1939) was born after an uneventful pregnancy and delivery, birthweight was 3150 g. Fetal movements were felt throughout the 2nd half of pregnancy. Respiratory difficulties, weak movements, and weak crying were noticed already at the age of 3 weeks. The child was admitted to the University Children's Clinic, Zürich (2881/39) at the age of 3 months, where advanced infantile SMA was diagnosed. The child died at the age of 6 months of pulmonaryo complications.

Case 4 (III.2; 21.8.1940-11.2.1941) was the brother of case 3 , he was similarly affected as his brother and died at the age of 6 months (report of the parents).

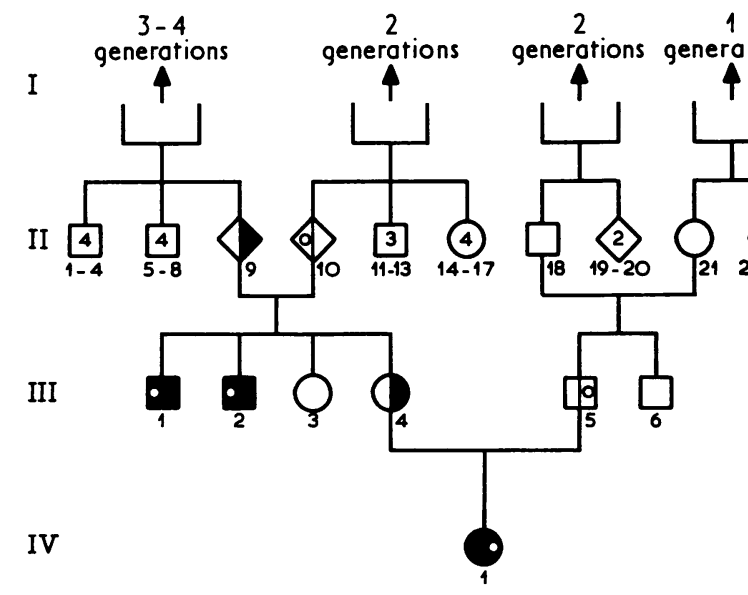

FIG. 2. Abbreviated pedigree of kindred 2. Infantile SMA in 2 uncles and their niece. Autosomal dominant inheritance with incomplete penetrance cannot be fully excluded, although no other case of SMA is known in generations I and II nor in any of the more distant generations. The presence of an activator allele in a parent of III.1 and III.2 (cases 3 and 4) and in father of IV.1 (case 5) would provide a plausible explanation. 
Case 5 (IV.1;29.3.1966-16.6.1967) was the only child in this family; pregnancy and delivery were uneventful. Fetal movements were felt and birth weight was $2930 \mathrm{~g}$. Movements were noticed to be weak right after birth. At 5 months the child was seen in the University Children's Clinic, Zürich where advanced SMA was diagnosed. EMG was compatible with this diagnosis. The child died of pulmonary complications at the age of 15 months.

Genealogy of Kindred 2. Cases 3 and 4 and the mother (III.4) of case 5 are sibs. No other cases of SMA and no consanguinity were found in this kindred although our genealogical studies extended back to between 2 and 4 generations. The parents of these sibs (II.9 and II.10) as well as III.4 and III. 5 came from different parts of the country. The father of case 5 (III.5) comes from a small village in the south-eastern part of Switzerland. A SMA patient with the same family name as III. 5 was found in that village, yet no relationship to III.5 could be established within the 4 preceding generations. Cases 3 and 5 revealed a very similar clinical course with early onset and very rapid development of severe muscular weakness. This may suggest that the same mutant gene was operative in both cases.

\section{Kindred 3 (Fig. 3)}

Case 6 (III.5; 13.9.1948-6.2.1949) was the product of the mother's 4th pregnancy. The delivery was allegedly 3 weeks early, but birth weight was $3500 \mathrm{~g}$. The child was weak and showed very little movement since birth. She was admitted to the University Children's Clinic, Berne $(76 / 49)$ at the age of 4 months. Her clinical findings were those of a far advanced SMA with already affected respiration. The child died at the age of 5 months of respiratory complications. Post mortem examination included a study of muscle and spinal cord and revealed characteristic findings of SMA.

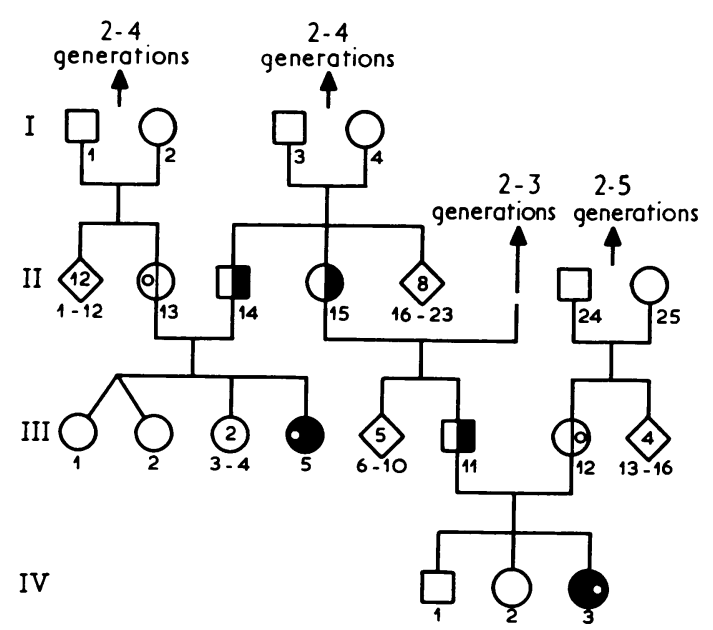

FIG. 3. Abbreviated pedigree of kindred 3. Infantile SMA in 2 first cousins once removed.
Case 7 (IV.3; 14.3.-23.10.1968) was the product of the mother's 3rd pregnancy, which was uneventful. Fetal movements were felt. Delivery was at term by Caesarean section and birth weight was $2980 \mathrm{~g}$. Weakness and reduced movements were noticed shortly after birth. At the age of 4 months she was admitted to the University Children's Clinic, Berne (23598/68) where a typical picture of severe infantile SMA was diagnosed. EMG and muscle biopsy was compatible with this diagnosis. The muscle (vastus lateralis) revealed very advanced alterations as they can be seen in advanced SMA as well as in severe myopathy. CPK was slightly elevated. The child, subsequently, developed pneumonia and died at the age of 7 months.

Genealogy of Kindred 3. The father (II.14) of case 6 and the paternal grandmother (II.15) of case 7 are sibs. No other cases of SMA and no consanguinity were found, although the patients' ancestry was followed back for between 3 and 6 generations. The course and clinical picture of the 2 cases were very similar and the same mutant gene may be assumed for both cases.

\section{Kindred 4 (Fig. 4)}

Case 8 (V.4; 19.2.1967-13.1.1969). This girl revealed the clinical picture of a classical infantile SMA (report from the Children's Hospital, Lucerne).

Case 9 (V.5; 18.6.-24.10.1964) was the product of the mother's 1st pregnancy. Fetal movements decreased towards the end of pregnancy. Delivery was at term and birth weight was $3720 \mathrm{~g}$. Muscular hypotonia and weakness were noticed soon after birth. At the age of 7 weeks the child was admitted to the University Children's Clinic, Zürich (No. 2445/64) where a severe infantile SMA was found. EMG and muscle biopsy were compatible with the clinical diagnosis. CPK was normal. The child died at the age of 4 months.

Case 10 (V.6; 27.8.-15.10.1965) was affected with the same disease as his brother (case 9) and died at the age of 7 weeks (report of the attending physician, $\mathrm{Dr}$ Marti, Lachen).

Genealogy of Kindred 4. Cases 9 and 10 were 3rd cousins of case 8 . Their common ancestors were traced back 4 generations to a couple who married in 1851. Other lines of the kindred, namely the ancestors of III.10, IV.7, and IV.16 are neither related with one another nor with the family of IV.8 and IV.14, the presumptive carriers of the SMA gene.

\section{Kindred 5 (Fig. 5)}

Case 11 (VI.2; 31.5.1956-15.9.1960) was the product of the 2nd pregnancy of his mother. Pregnancy was uncomplicated and fetal movements were felt throughout the 2nd half of the pregnancy. Delivery was normal and birthweight was $4000 \mathrm{~g}$. He appeared fairly strong during the first few months but never learned to sit or stand. After the 9th month he became progressively 


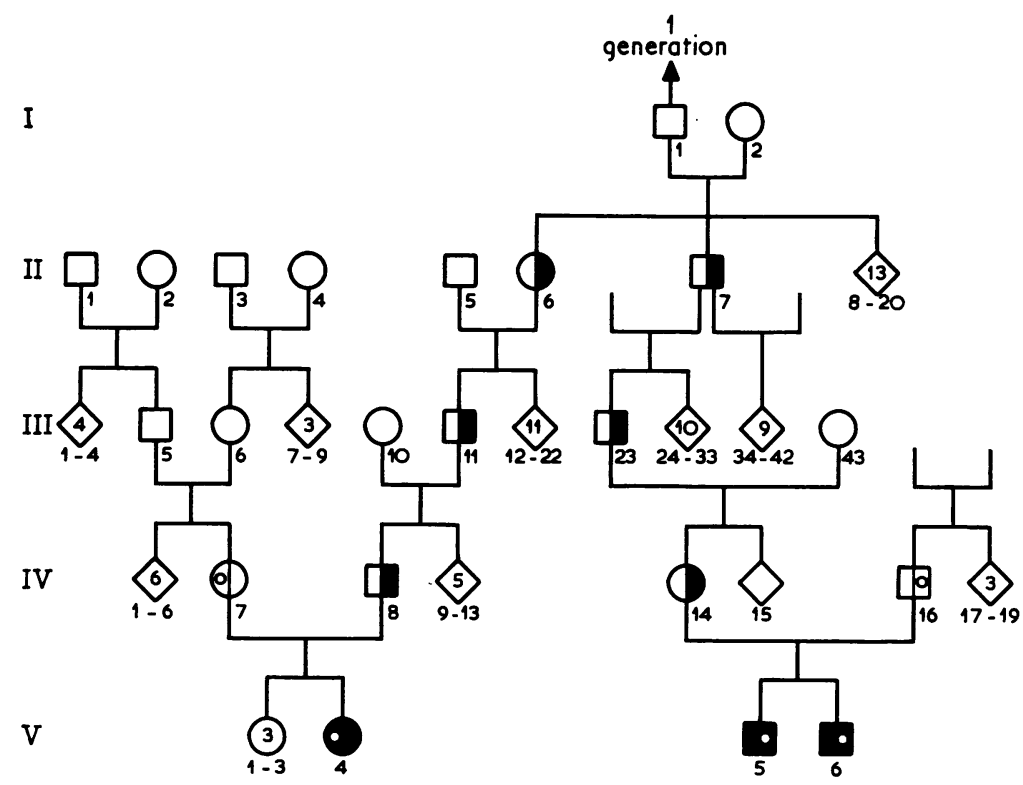

FIG. 4. Abbreviated pedigree in kindred 4. Infantile SMA in 3rd cousins.

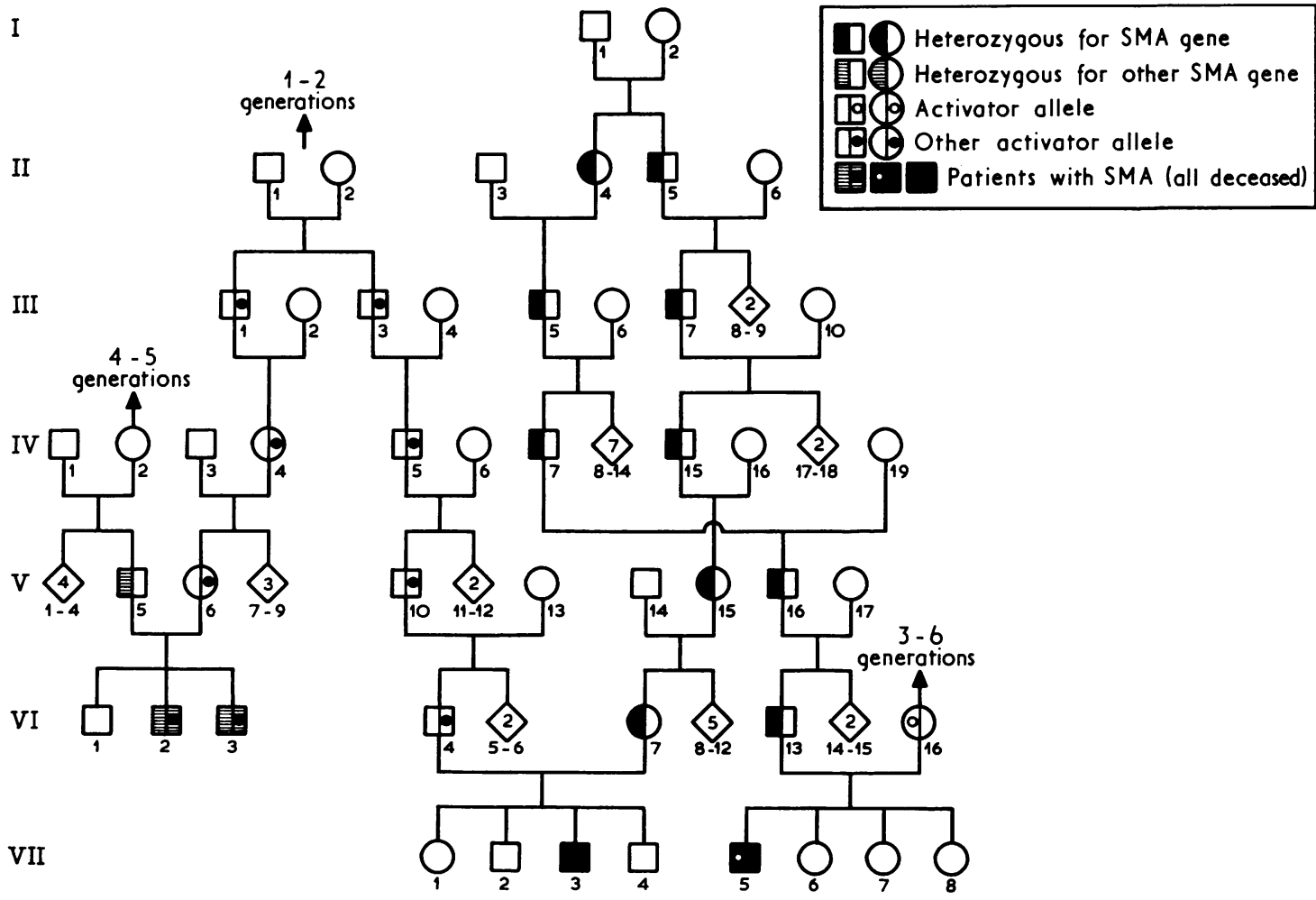
FIG. 5. Abbreviated pedigree of kindred 5. Infantile SMA in 3rd cousins once removed (VI.2, VI.3, and VII.3; cases 11, 12, and 13) and
in 5th cousins (VIII.3 and VII.5; cases 13 and 14). 
weaker. At 20 months of age he was admitted to the University Children's Clinic, Berne (1323/58) where a diagnosis of infantile SMA was made. There was severe muscular hypotonia, weak cry and weakness of extremities and intercostal muscles. Fasciculations were noticed in his tongue. The child died of pneumonia at the age of 4 years 4 months.

Case 12 (VI.3; 5.1.1959-31.12.1960) had allegedly the same disease as his brother (case 11) and died at the age of almost 2 years (report of the attending physician, Dr J. Haas, Burgdorf).

Case 13 (VII.3; 16.2.-3.8.1958) was the product of his mother's 3rd, uncomplicated pregnancy. Fetal movements were strong. Delivery was normal and birth weight was $3600 \mathrm{~g}$. He appeared vigorous during the first 4 months but his movements became weaker thereafter. He was admitted to the University Children's Clinic, Berne (1988/58) where a diagnosis of severe infantile SMA was made. He died of pulmonary complications at the age of $5 \frac{1}{2}$ months. At necropsy examination of muscle and spinal cord confirmed the clinical diagnosis SMA.

Case 14 (VII.5; 13.5.-30.12.1960) was born by forceps delivery after an uneventful pregnancy. Birth weight was $3050 \mathrm{~g}$. Movements became weak after the 3rd month. At 6 months he was admitted to the University Children's Clinic, Zürich $(1228 / 60)$ where a diagnosis of infantile SMA was made. EMG and muscle biopsy were consistent with this diagnosis. The child died at the age of 7 months.

Genealogy of Kindred 5. There are 4 cases of infantile SMA distributed over 3 sibships and 2 generations in this kindred. Cases 13 and 14 are 5th cousins related to each other through common ancestors whose marriage dates back to 1787 . The clinical course of both cases was very similar and suggests a common mutant gene $A$. The SMA of the cases 11 and 12 took a somewhat longer course than that of cases 13 and 14 . Cases 11 and 12 are brothers and 3rd cousins of the father (VI.4) of case 13 and are not related with case 14 . The clinical and genealogical indications are that the SMA of cases 11 and 12 is due to a different mutant gene $\mathrm{A}$ than that of cases 13 and 14. No other cases of SMA and no consanguinity were found in this large kindred.

\section{Kindred 6 (Fig. 6)}

Case 15 (III.2; 26.3.1927-21.10.1943) has previously been reported (Hanhart, 1945/1946, pp. 114 and 116). This patient developed slow progressive muscular weakness after the age of 6 months. Between the ages of 2 and 12 years he was seen by neurologists and orthopaedic surgeons of the University of Zürich (15536/30) and the Orthopaedic Clinic (4011/40) and a diagnosis of infantile SMA with slow progression was made.

Case 16 (IV.1; 6.2.-3.10.1940) was the product of the 1st pregnancy of his mother. She did not experience any fetal movements. The child was weak and

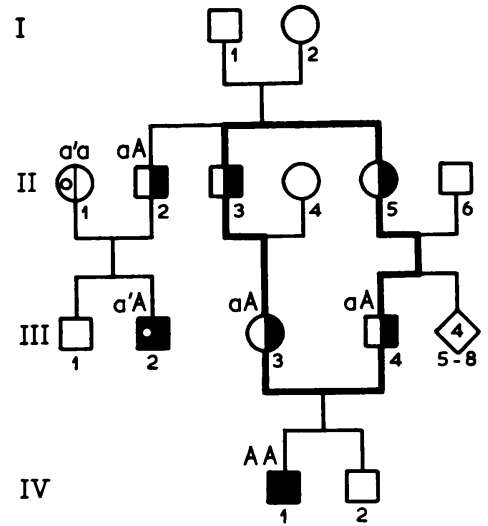

FIG. 6. Abbreviated pedigree of kindred 6. Infantile SMA in first cousins once removed and close consanguinity of the parents of IV.1 (case 16).

motionless since birth, respiratory muscles became involved later, bronchopneumonia developed and death ensued at 8 months. The clinical diagnosis SMA was confirmed by the necropsy (S. 1105/1940 of the Pathological Institute, University of Zürich).

Genealogy of Kindred 6. The father (II.2) of case 15, the paternal grandmother (II.5), and the maternal grandfather (II.3) of case 16 were sibs, thus the parents (III.3 and III.4) of case 16 were first cousins. The SMA of case 15 showed a slow onset and slow progression, ending with the patient's death after a course of 16 years. In contrast the SMA of case 16 began during prenatal life, was severe from the beginning, and led to the patient's death at the tender age of 8 months.

\section{Discussion}

The 6 kindreds reported here present cases of infantile progressive spinal muscular atrophy (SMA) in more than one sibship and even in 4 cases in more than one generation. In some of them, notably in kindreds 4 and 5 the affected individuals were distantly related with many healthy relatives between them. The question that therefore arises is whether there is a coincidental association of causally unrelated SMAs or whether it is possible that they have a common genetic origin and if, so, whether they fit any of the known patterns of genetic transmission?

Autosomal recessive traits do not manifest themselves phenotypically in more than one sibship of a generation. Exceptions to this rule are conditions with high gene frequency as for instance mucoviscidosis or kindreds with multiple consanguineous marriages. The frequency of the SMA genes is presumably not higher than that of many other autosomal recessive conditions. Even if we assume one gene to be responsible for all SMAs, its frequency would not be higher than 1 in 
130-150. Gene frequencies of such magnitude preclude random association of autosomal recessive disease in the manner presented here.

Autosomal dominant inheritance with incomplete penetrance is likewise to be excluded certainly for kindreds 4 and 5 and possibly for kindred 3 since too many healthy relatives interconnect the SMA patients. Assuming autosomal dominance with incomplete penetrance for instance for kindred 5, notably of the cases 13 and 14 would mean that the mutant gene A had remained phenotypically silent through 6 preceding generations. This is far beyond the acceptance rate of nonpenetrance for a dominant trait.

$\mathrm{X}$-linked recessive inheritance is excluded by the various instances of male to male transmission of the mutant gene in the kindreds 4,5 , and 6 .

The distribution of the disease in the kindreds 4 and 5 and possibly 3 could best be explained by the above mentioned hypothesis of the activator allele $a^{\prime}$ being necessary to make the information transmitted by the mutant allele A phenotypically apparent. The activator allele $a^{\prime}$ has been estimated (Becker, 1966) to be 10 to 15 times more frequent than the allele A. Random association of the activator allele $\mathrm{a}^{\prime}$ more than once into a kindred is thus quite possible. It is acceptable to assume, therefore, that 2 unrelated individuals introduced the activator allele $\mathrm{a}^{\prime}$ into the kindreds 4 and 5 (see IV.7 and IV.16 in Fig. 4 and VI.4 and VI.16 in Fig. 5).

However, kindred 5 deserves one further comment. Here SMA was found in 3 different sibships; for one of them (see Fig. 5) one has to assume another mutant gene $A$ than for the other 2 sibships. As Fig. 5 shows, 2 mutant genes $\mathrm{A}$ and 2 activator alleles have to be assumed to explain this pedigree. In this connection it is interesting to note that the clinical course of cases 11 and 12 (VI.2 and VI.3) differed considerably from that of cases 13 and 14 (VII.3 and VII.5) indicating perhaps a different mutant gene $A$ ?

The SMA in the kindreds 1 and 2 could perhaps be due to autosomal dominant inheritance with incomplete penetrance. However, at least for kindred 1 it is plausible to assume that the spouses II. 9 and II.12 brought the activator allele into the kindred. For kindred 2 the mode of inheritance remains unclear, although we have used the same symbols for the alleles as in the other pedigrees.

The genetics in kindred 6 deserves a separate interpretation. The parents of case 16 (IV.1) are first cousins, thus autosomal recessive inheritance could account for this case, but not for case 15 (III.2). One could assume that the mother (II.1) of the latter is heterozygous for the activator gene $a^{\prime}$, while the father (II.2), who is a sib of the grandparents (II.3 and II.5) of case 16, carries the mutant gene A. If this assumption is correct the genotypes of the 2 patients could be $\mathrm{Aa}^{\prime}$ (case 15) and AA (case 16). We wonder whether or not the comparatively more severe clinical course of case 16 could be related to his genotype AA.

The hypothesis of the allelomorphic activator gene $a^{\prime}$ being necessary to produce manifest SMA in heterozygous carriers of the mutant gene $A$ is still not definitely proven. The observations presented here, certainly those of the kindreds 3,4 , and 5 and possibly of 1 and 6 present further presumptive evidence for the existence of this new geneticmechanism.

Becker (1966) described this new mode of inheritance initially for the so called KugelbergWelander's disease or atrophia musculorum spinalis pseudomyopathica, which-according to the original description of Kugelberg and Welander (1956) -represents a type of SMA with onset between 2 and 17 years, slow progression, and long survival. In some kindred cases of so called KugelbergWelander's disease occurred together with cases of infantile progressive SMA (Brandt, 1950; Thieffry, Arthuis, and Bargeton, 1955; Hurwitz, Lapresle, and Garin, 1961). Finally, Zellweger et al (1969), as well as White and Blaw (1971) observed 3 families with this type of inheritance, where only infantile progressive SMA occurred. The cases reported herece confirm the latter observation. Thus various clinical? forms of SMA can display this new hereditary variant. Among the diversified hereditary patterns of SMA it may even be quite frequent. Our investigations of SMA in Switzerland revealed this variant in at least 5 of 104 families, ie, in about $5 \%$ of all familial spinal muscular atrophies.

\section{Summary}

Investigations of the genetics of 150 cases of infantile spinal muscular atrophy collected from various children's hospitals in Switzerland yielded 6 kindreds with a peculiar distribution of spinal muscular atrophy (SMA) in 2 generations or 2 or 3 sibships. The hereditary pattern in these kindreds could not be readily explained by any of the conventional modes of Mendelian inheritance. It can be understood if one assumes a mutant gene which in the heterozygous state does produce manifest SMA only in presence of an allelomorphic activator gene. This latter allele appears to be sufficiently frequent to account for the occurrence of SMA in individuals who are quite distantly related with each other. This new genetic variant was found in about $5 \%$ of the SMA families collected in this area. 
The help of the various Swiss children's hospitals in procuring the case material is gratefully acknowledged. We are particularly grateful to Dr H. Moser (University Children's Clinic, Berne) for his help and interest in this work.

\section{REFERENCES}

Becker, P. E. (1964). Atrophia musculorum spinalis pseudomyopathica. Zeitschrift für Vererbungs- und menschliche Konstitutionslehre, 37, 192-220.

Becker, P. E. (1966). Krankheiten mit hauptsächlicher Beteiligung von Pyramidenbahn, Vorderhorn und bulbären motorischen Kernen. Humangenetik, V, No. 1,314-410. Thieme, Stuttgart.

Brandt, S. (1950). Werdnig-Hoffmann's Infantile Progressive Muscular Atrophy. Munksgaard, Copenhagen.

Hanhart, E. (1945/1946). Die infantile progressive spinale Muskelatrophie (Werdnig-Hoffmann) als einfach-rezessive subletale Mutation auf Grund von 29 Fällen in 14 Sippen. Helvetica Paediatrica Acta, 1, 110-133.

Hurwitz, L., Lapresle, J., and Garcin, R. (1961). Atrophie musculaire neurogène de topographie proximale et symetrique simulant une myopathie. Revue Neurologique, 104, 91-107.
Kirchhof, J. K. J., Kumral, K., and Fadiloglu, S. (1962). Späte Manifestation mit protrahiertem Verlauf bei Werdnig-Hoffmannscher spinaler Muskelatrophie. Nervenarzt, 33, 442-446.

Kugelberg, E. and Welander, L. (1956). Heredofamilial juvenile muscular atrophy simulating muscular dystrophy. Archives of Neurology and Psychiatry, 75, 500-509.

Thieffry, S., Arthuis, M., and Bargeton, E. (1955). Quarante cas de maladie de Werdnig-Hoffmann avec onze examens anatomiques. Revue Neurologique, 93, 621-644.

White, N. R. and Blaw, M. E. (1971). An unusual inheritance pattern for spinal muscular atrophy. Developmental Medicine and Child Neurology, 13, 621-624.

Wohlfart, G., Fex, J., and Eliasson, S. (1955). Hereditary proximal spinal muscular atrophy-a clinical entity simulating progressive muscular dystrophy. Acta Psychiatrica et Neurologica, 30, 395406.

Zellweger, H. (1971). The genetic heterogeneity of spinal muscular atrophy (SMA). Birth Defects: Original Article Series, VII, 7, 82-89. National Foundation-March of Dimes, New York.

Zellweger, H., Schneider, H. J., Schuldt, D. R. and Mergner, W. (1969a). Heritable spinal muscular atrophies. Helvetica Paediatrica Acta, 24, 92-105.

Zellweger, H., Schneider, H., and Schuldt, D. R .(1969b). A new genetic variant of spinal muscular atrophy. Neurology, 19, 865869. 